\title{
Inorganic concepts relevant to metal binding, activity, and toxicity in a biological system
}

\author{
James D. Hoeschele ${ }^{\mathrm{a}}$, James E. Turner ${ }^{\mathrm{b}}$ and M. Wendy England ${ }^{\mathrm{b}}$ \\ ${ }^{a}$ Department of Chemistry, University of Michigan, $930 \mathrm{~N}$. University Ave., Ann Arbor, \\ MI 48109-1055, USA

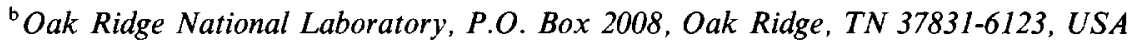

\begin{abstract}
Selected physical and inorganic concepts and factors which might be important in assessing and/or understanding the fate and disposition of metal compounds in a biological environment are reviewed. The stereochemistry (geometry), thermodynamic stability, redox properties, and intrinsic reactivity/lability are properties of metal compounds which can have a major influence on metal-target binding and on the eliciting of activity/toxicity. Concepts and factors are illustrated with appropriate examples where possible. Efforts to correlate the toxicity of metal compounds with a suitable indicator of toxicity should be expanded to include other parameters or combinations of parameters.
\end{abstract}

\section{INTRODUCTION}

The response elicited when a metal species (electrophile) interacts with a biological system is dependent upon a complex set of interrelationships involving physical, chemical, biological, and pharmacological factors. To a first approximation, physico-chemical factors associated with the intrinsic nature of both the metal system and the type of biological ligands present are primary determinants (in a broad sense) as to whether the interaction will be beneficial (e.g., as in the case of essential trace elements and therapeutic agents), detrimental (toxic agents), or innocuous to the organism. In order to better understand the molecular basis of such a response, one needs to characterize the metal-biological system interaction in terms of the nature of the reacting species and the types of products (or lesions) formed. While the characterization of species in a simple chemical system (wherein one has control over all the reaction parameters) is a relatively straight-forward task, the characterization of metal species in a biological medium is an exceedingly complex if not an intractable problem. Thus, one has to rely on basic chemicalbiological information, fundamental concepts, and information obtained from simplified model systems to gain insight into what might be happening

0048-9697/91/\$03.50 (C) 1991 Elsevier Science Publishers B.V. All rights reserved 
TABLE 1

Factors which contribute to the binding, toxicity, and activity of a metal system in a biological environment

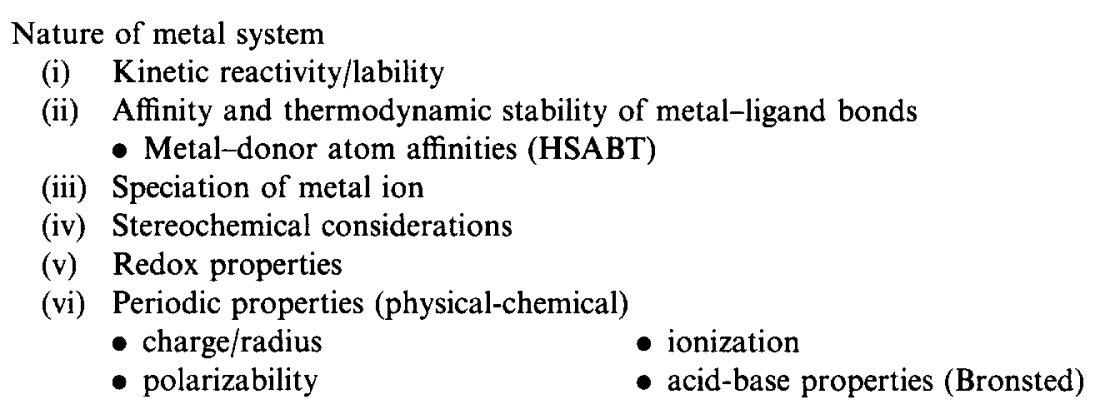

Nature of biological system

(i) Availability of ligands with high affinity for metal ions

- $\mathrm{S}, \mathrm{N}, \mathrm{O}$ donor systems

(ii) Capability for chelation

- enhance stability of M-L bond

in order to address the important questions concerning (a) the nature of the active/toxic species and (b) the origin/mechanism of activity/toxicity.

The purpose of this paper is to review selected physical and inorganic concepts and factors which might be important in assessing and/or understanding the fate and disposition of a metal system in a biological environment. Hopefully, such inquiries will ultimately permit us to understand, rationalize, and predict differences and trends in biological effects as a function of the basic nature of a metal system and, in optimal cases, serve as input to a system of guidelines for the notion of "Chemical Dosimetry".

The plan of this paper is to first review, in general terms, the basic principles of the crystal field theory (CFT), a unifying theory of bonding in metal complexes [1]. This will provide the necessary theoretical background for the subsequent discussion of selected concepts and factors (Table 1).

\section{CRYSTAL FIELD THEORY (CFT)}

The CFT is an extremely important theory of bonding in transition metal complexes [2]. Although the CFT was derived strictly on the basis of electrostatic arguments, the application of this theory forms the basis of predicting the structure, stability, redox properties, and kinetic lability/reactivity of metal complexes as well as accounting for certain trends in the physico-chemical properties of metal complexes [3]. The following is a brief description of the CFT using an octahedral complex as an example [4]: as the negatively-charged 
(- Theory of Bonding in T.M. Complexes

- Basis for the Prediction of Structure, Stability, Lability of Complexes; Accounts for Trends in Physical-Chemical Properties
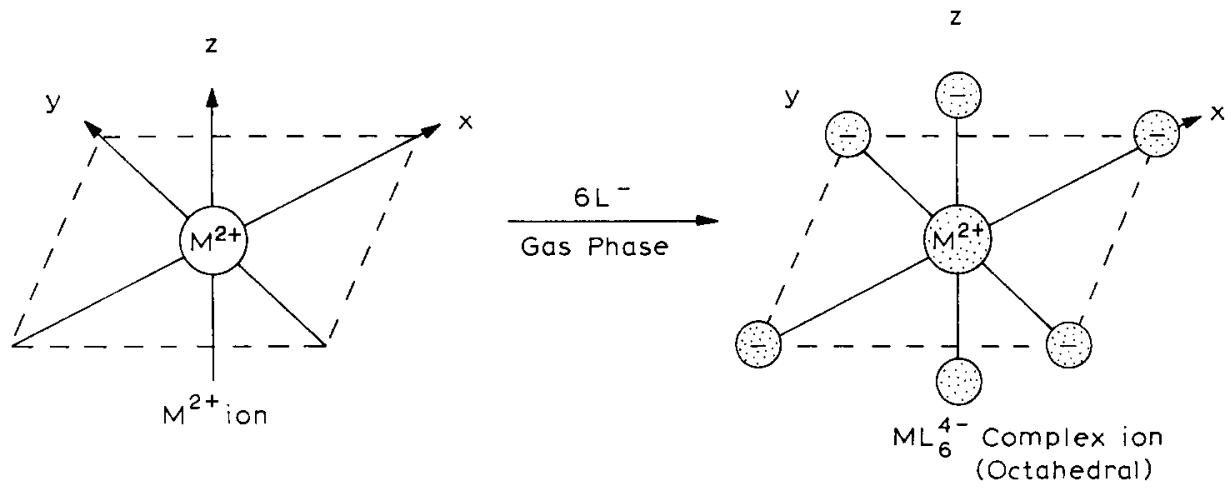

Fig. 1. Schematic representation of the formation of an octahedral complex ion from the electrostatic interaction of a $\mathrm{M}^{2+}$ cation and six $\mathrm{L}^{-}$anions in the gas phase.

ligands, $\mathrm{L}^{-}$, approach the positively-charged metal ion, $\mathrm{M}^{2+}$, in the gas phase (Fig. 1), the five-fold degenerate $d$-orbitals become differentiated in the presence of the electrostatic field of the ligands. Orbitals oriented in the direction of the incoming ligands $\left(d_{z^{2}}, d_{x^{2}-y^{2}}\right)$ are preferentially raised in energy, while those oriented away from the ligands are lowered in energy $\left(d_{x y}\right.$, $d_{\mathrm{xz}}, d_{y z}$; Fig. 2). The availability of $d$ electrons can stabilize the system by preferential rather than random filling of the low lying levels $\left(t_{2 g}\right)$. The gain in bond energy by preferential filling is called the "crystal field stabilization energy" (CFSE). Referring to the crystal field splitting diagram (Fig. 2), the order of filling ( $10 \mathrm{e}^{-}$occupancy) is such that the first three electrons go into the lower levels $\left(t_{2 \mathrm{~g}}\right)$. Addition of a fourth electron can go either into the $t_{2 \mathrm{~g}}$ or into the upper levels $\left(e_{\mathrm{g}}\right)$ depending on the energy required for pairing (in the $t_{2 \mathrm{~g}}$ ) relative to the magnitude of the difference in energy, $\Delta$, between the upper and lower levels. If the splitting (i.e., $\Delta$ ) is small as in a weak crystal field, the electron can occupy the $e_{\mathrm{g}}$ level leading to a high spin complex, or if $\Delta$ is too large (as in a strong crystal field) the electron will pair up in the $t_{2 \mathrm{~g}}$ level giving rise to a low spin complex. Thus, two general types of complexes involving different spin states can result depending on the strength of the crystal field - the so-called high and low spin complexes. The magnitude of $\Delta$ for a divalent, $\mathrm{M}\left(\mathrm{H}_{2} \mathrm{O}\right)_{6}^{2+}$, and trivalent, $\mathrm{M}\left(\mathrm{H}_{2} \mathrm{O}\right)_{6}^{3+}$, aqua ions (from spectral data) is $\sim 10000 \mathrm{~cm}^{-1}(28.6 \mathrm{kcal})$ and $\sim 20000 \mathrm{~cm}^{-1}(57.2 \mathrm{kcal})$, respectively. For the first to third row transition metal complexes of the same type (e.g., $\mathrm{MX}_{6}^{3-}$ ), $\Delta$ increases in the relative ratio of 1:1.5: $\sim 2$, respectively. The energy splitting, $\Delta$, is also a function of the type of donor-atom ligand 


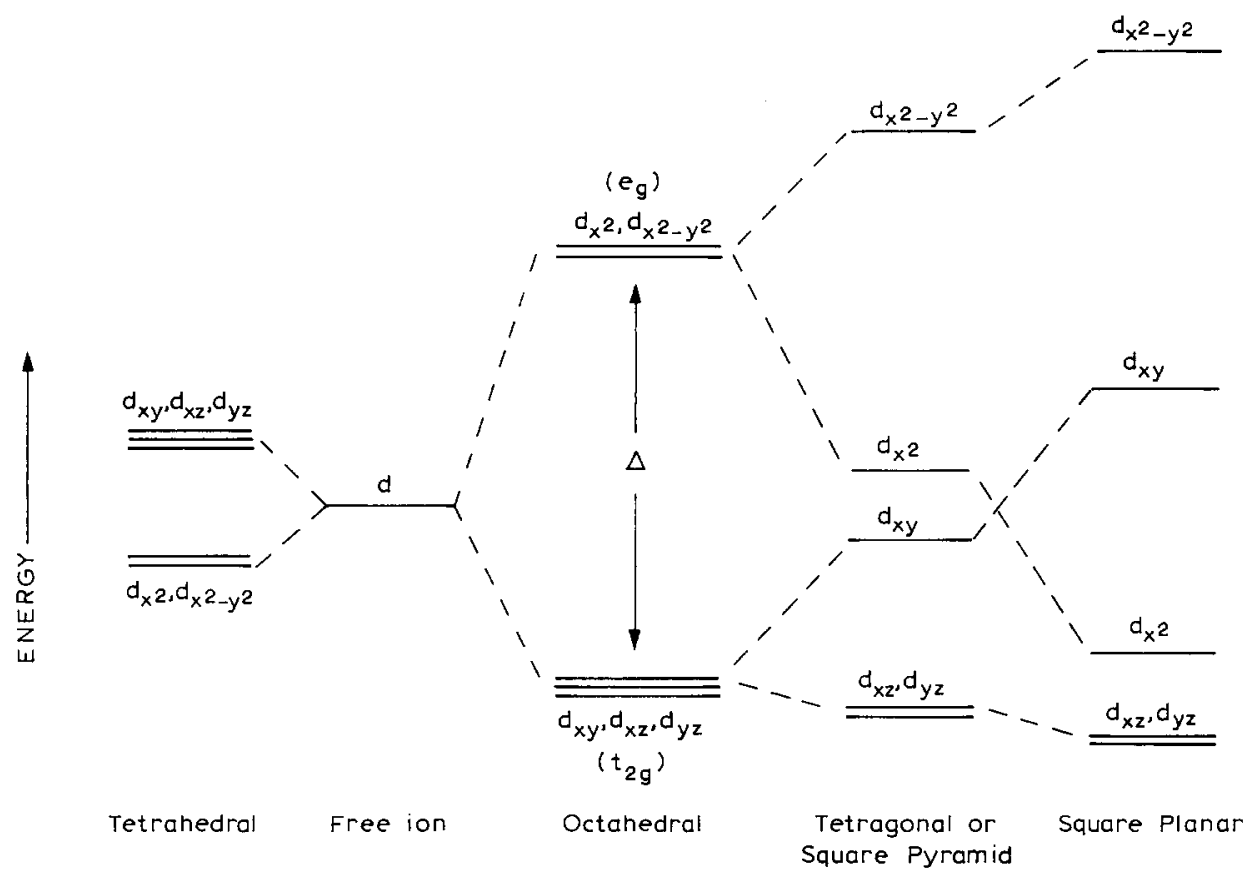

Fig. 2 Crystal field splitting of the $d$ orbitals of a central metal ion in regular complexes as a function of geometry: tetrahedral, octahedral, tetragonal, and square-planar. The electrostatic field of the ligands causes the five-fold degenerate $d$ orbitals of the free ion to become differentiated (split). For regular octahedral geometry the splitting leads to two degenerate higher energy orbitals $\left(e_{\mathrm{g}}\right)$ and three degenerate lower energy orbitals $\left(t_{2 \mathrm{~g}}\right)$. The difference in energy between the $\left(e_{\mathrm{g}}\right)$ amd $\left(t_{2 \mathrm{~g}}\right)$ is designated as $\Delta$.

attached to the metal. The order for common ligands [5] is:

$$
\begin{aligned}
& \mathrm{I}^{-}<\mathrm{Br}^{-}<\mathrm{CI}^{-} \sim \underline{\mathrm{S} C N^{-}} \sim \mathrm{N}_{3}^{-}<(\mathrm{EtO})_{2} \mathrm{PS}_{2}^{-}<\mathrm{F}^{-}<\left(\mathrm{NH}_{2}\right)_{2} \mathrm{CO} \\
& <\mathrm{OH}^{-}<\mathrm{C}_{2} \mathrm{O}_{4}^{2-} \sim \mathrm{H}_{2} \mathrm{O}<\underline{\mathrm{NCS}^{-}} \sim \mathrm{H}^{-}<\mathrm{CN}^{-}<\underline{N H}_{2} \mathrm{CH}_{2} \mathrm{CO}_{2}^{-} \\
& <\mathrm{NH}_{3} \sim \mathrm{C}_{5} \mathrm{H}_{5} \mathrm{~N}<\text { en } \sim \mathrm{SO}_{3}^{2-}<\mathrm{NH}_{2} \mathrm{OH}<\mathrm{NO}_{2}^{-}<\text {phen } \\
& <\mathrm{CH}_{3}^{-}<\mathrm{CN}^{-}
\end{aligned}
$$

(This series is known as the spectrochemical or Fajans-Tsuchida series; the underlined atoms are the donor atoms.)

In general, the predicted order of decreasing tendency of donor-ligands to cause spin-pairing is $\mathrm{C}>\mathrm{N}>\mathrm{O}>\mathrm{S}>\mathrm{F}>\mathrm{Cl}>\mathrm{Br}$, whereas the actual order found is: $\mathrm{S}>\mathrm{O}$ and $\mathrm{Cl}, \mathrm{Br}>\mathrm{F}$.

GEOMETRY-STEREOCHEMISTRY OF METAL SYSTEMS (CFT Predictions)

Knowledge of the geometry of a metal system permits us to understand how different metals can perform similar functions in processes wherein the 
TABLE 2

Geometry of metal systems predicted by the crystal field theory ${ }^{a}$

\begin{tabular}{cllr}
\hline$d$ system & Example & Four-coordinate & Six-coordinate \\
\hline $\begin{array}{c}\text { High-spin } \\
0^{\mathrm{b}}\end{array}$ & $\mathrm{Mg}^{2+}, \mathrm{Ca}^{2+}$ & & \\
$10^{\mathrm{b}}$ & $\mathrm{Zn}^{2+}, \mathrm{Cd}^{2+}$ & Tetrahedral & Octahedral \\
5 & $\mathrm{Mn}^{2+}, \mathrm{Fe}^{3+}$ & & \\
9 or 4 & $\mathrm{Cu}^{2+}, \mathrm{Cr}^{2+}$ & Square-planar & Tetragonal \\
8 or 3 & $\mathrm{Ni}^{2+}, \mathrm{Cr}^{3+}$ & Tetrahedral & Octahedral \\
7 or 2 & $\mathrm{Co}^{2+}, \mathrm{Ti}^{2+}$ & Tetrahedral & Octahedral \\
6 or 1 & $\mathrm{Fe}^{2+}, \mathrm{Ti}^{3+}$ & Tetrahedral & Octahedral \\
& & (almost) & (almost) \\
Low-spin & & & \\
1 or 2 & & Tetrahedral & (almost) \\
3 & & Tetrahedral & Octahedral \\
4 & & & (almost) \\
& & & Tetragonal \\
6 & & Square-planar & Tetragonal \\
\hline
\end{tabular}

${ }^{a}$ From R.S. Nyholm [6].

${ }^{\mathrm{b}} \mathrm{A} d$ system of 0 or 10 corresponds to a non-transition metal.

stereochemistry is critical to the selectivity/specificity of the reaction processes. Relevant examples are:

(i) metalloenzymes (synthetases) containing $\mathrm{Mg}$ (II) or $\mathrm{Mn}$ (II) acting in similar roles wherein there are strict stereoselective requirements;

(ii) choice of metal systems for optimal antitumor activity for which most of the useful complexes are square-planar $\mathrm{Pt}(\mathrm{II})$ complexes.

Based on the magnitude of $\Delta$ and the nature of the bound ligands, the geometries predicted for the various metal systems [6] are tabulated in Table 2. The generalities of these predictions are as follows:

(i) geometries of metal complexes fall into four basic types of structures: tetrahedral, octahedral, square-planar, and tetragonal, for which both high and low spin states are possible (see Table 2 and Fig. 2);

(ii) all non-transition elements $\left(d^{0}, d^{10}\right)$ and $d^{5}$ systems (e.g., $\mathrm{Mn}^{2+}$ and $\mathrm{Mg}^{2+}$ ) are either tetrahedral (four-coordinate) or octahedral (six-coordinate);

(iii) substantially different geometries are predicted for high and low spin complexes for the $d^{8}$ metal systems [e.g., $\mathrm{Ni}(\mathrm{II}), \mathrm{Pd}(\mathrm{II}), \mathrm{Pt}(\mathrm{II})$, and $\mathrm{Au}(\mathrm{III})]$. 


\section{TABLE 3}

Kinetic predictions $s^{a}$ of lability/reactivity based on the contribution of crystal field stabilization energy (CFSE) to the activation energy, $E_{\mathrm{a}}^{\dagger}$

Labile/ $d^{0}, d^{1}, d^{2}, d^{5}$ (high), $d^{6}$ (high), $d^{7}$ (high

Inert $/ d^{6}>d^{3}>d^{4}$ (low) $>d^{5}$ (low); $d^{8}$

Transition metal systems which appear to have labilities/reactivities falling within the "window of lability"

Ist row/

Only $\mathrm{Co}(\mathrm{III})\left(d^{6}\right.$-low spin); $\mathrm{Cr}(\mathrm{III}), d^{3}$

2nd and 3rd rows

$d^{6}: \operatorname{Rh}(\mathrm{III}), \operatorname{Ir}(\mathrm{III}), \operatorname{Ru}(\mathrm{II}), \mathrm{Pt}(\mathrm{IV})$

$d^{5}: \operatorname{Ru}(\mathrm{III}), \mathrm{Os}(\mathrm{III})$

$d^{8}: \operatorname{Pt}(\mathrm{II}), \mathrm{Au}(\mathrm{III}), \mathrm{Pd}(\mathrm{II})$

Remote possibilities

$d^{3}: \operatorname{Mo}(\mathrm{III}), \mathrm{W}(\mathrm{III}), \operatorname{Re}(\mathrm{IV})$

${ }^{a}$ Independent of mechanism $S_{n} 1, S_{n} 2$ or Intermediate.

\section{KINETIC REACTIVITY/LABILITY}

The intrinsic nature of the metal ion largely determines the reactivity of the metal complex. This is especially relevant for the use of metal complexes as therapeutic agents or to the reaction products of aquated cations with biological substrates (ligands). Metal systems vary in lability from extremely labile to essentially substitutionally-inert systems. (A labile complex is one that undergoes a substitution reaction within the time of mixing [7].)

Based on the contribution of the CFSE to the activation energy, $E_{\mathrm{a}}^{\ddagger}$, and experimental measurements, one can make the following generalizations about the lability of metal systems (Table 3 ) [8].

(i) Non-transition elements $\left(d^{0}, d^{10}\right)$ are extremely labile as judged, for example, by the rate of exchange of bulk $\mathrm{H}_{2} \mathrm{O}$ for $\mathrm{H}_{2} \mathrm{O}$ bound in the first coordination sphere (Fig.3). To a first approximation, the exchange rate is a function of the charge on the aqua metal ion. In general, the alkali, alkaline earth (except Be), M(III) cations of the lanthanide elements, and the divalent metal ions of the first-row transition elements are all very labile with characteristic rate constants ranging from $10^{4}$ to $10^{10} \mathrm{~s}^{-1}$. The high lability of essential cations $\left(\mathrm{Na}^{+}, \mathrm{K}^{+}, \mathrm{Ca}^{2+}, \mathrm{Mg}^{2+}\right)$ is consistent with the idea that these ions are essentially "free" or unbound in the body and are associated with catalytic sites of enzymes, but do not inhibit their activity. The very slow rates of exchange of the aqua cations, $\mathrm{Cr}\left(\mathrm{H}_{2} \mathrm{O}\right)_{6}^{3+}$ and $\mathrm{Rh}\left(\mathrm{H}_{2} \mathrm{O}\right)_{6}^{3+}, 3 \times 10^{-6}$ and $4 \times 10^{-8} \mathrm{~s}^{-1}$, respectively, extends the spread in rates to at least $10^{18}$. 


$$
M\left(\mathrm{H}_{2} \mathrm{O}\right)_{6}^{n+}+L \stackrel{k_{a}}{\underset{k_{b}}{\rightleftharpoons}} M\left(\mathrm{H}_{2} \mathrm{O}\right)_{6^{+}}^{n+} L \stackrel{k_{c}}{\underset{k_{d}}{\rightleftharpoons}} M\left(\mathrm{H}_{2} \mathrm{O}\right)_{5} L^{n+}+\mathrm{H}_{2} \mathrm{O}
$$

Periodic Group
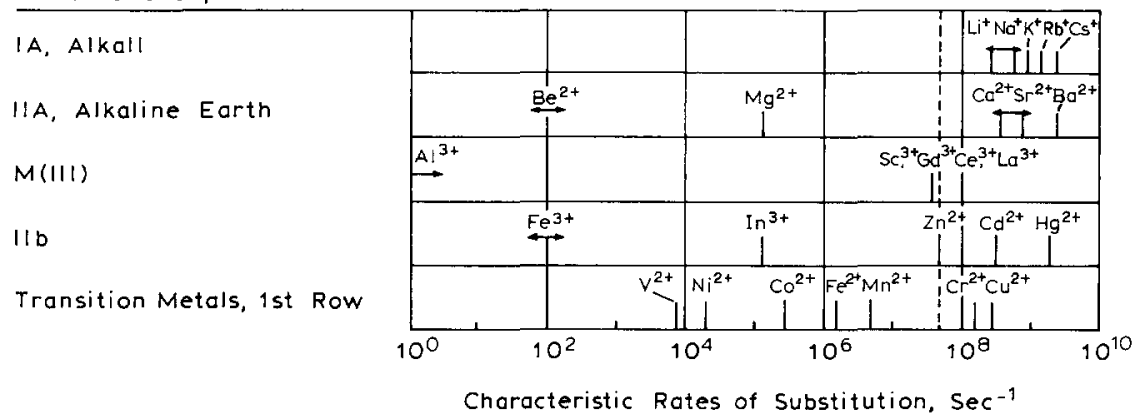

(3) Spread in Rates: $10^{10}\left(10^{18}\right.$ Considering $\left.\mathrm{Cr}^{3+}, 3 \times 10^{-6} ; \mathrm{Rh}^{3+}, 4 \times 10^{-8} \mathrm{sec}^{-1}\right)$

- Etfect of Charge/Radius Ratio

- Classical Reactivity Order (Divalent Metals): $\mathrm{Mn}>\mathrm{Fe}>\mathrm{Co}>\mathrm{Ni} \ll<\mathrm{Cu}$

Fig. 3. Characteristic rate constants, $k_{\mathrm{c}}$ (in s ${ }^{-1}$ ), for $\mathrm{H}_{2} \mathrm{O}$ substitution in the inner coordination sphere of aqua metal ions. Data of M. Eigen [22].

(ii) The classical reactivity order for first-row divalent cations is:

$$
\mathrm{Mn}>\mathrm{Fe}>\mathrm{Co}>\mathrm{Ni} \ll \mathrm{Cu}
$$

(iii) Inertness to substitution increases from first to third row metals (as $Z$ increases) for metal oxidization states with the same electronic configuration (Table 4). This periodic trend in inertness is reflected in the fact that Mo is the only "essential" transition metal found in biological systems that is not a first-row transition metal. While first-row metals are, for the most part, labile, second- and third-row transition metals appear to be too strongly bonded and inert to perform metabolic functions. However, it is precisely the properties of stability and inertness that appear to make Pt(II) and may make other

\section{TABLE 4}

Inertness to substitution increases in going from 1 st to 3 rd row transition metals for metal oxi-

\begin{tabular}{|c|c|c|c|c|}
\hline $\begin{array}{l}\text { Periodic } \\
\text { group }\end{array}$ & $k$ & VIIIA & VIIIA & $k$ \\
\hline 1st row & $3 \times 10^{4}$ & $\operatorname{Co}($ III $)$ & $\operatorname{Ni}(\mathrm{II})$ & $5 \times 10^{6}$ \\
\hline 2nd row & $2 \times 10^{2}$ & $\mathbf{R h}(\mathrm{III})$ & $\operatorname{Pd}(\mathrm{II})$ & $10^{5}$ \\
\hline 3rd row & 1.0 & $\operatorname{Ir}($ III $)$ & $\operatorname{Pt}(\mathrm{II})$ & 1.0 \\
\hline
\end{tabular}
dation states with the same electronic configuration. Relative rates of substitution, $k, M^{-1} \mathrm{~s}^{-1}$

Reduced susceptibility to hydrolysis as atomic number increases. 


\section{WINDOW OF LABILITY}

\begin{tabular}{|c|c|c|}
\hline Too Labile & & $\frac{\text { Too Inert }}{\text { Unreactive }}$ \\
\hline $\begin{array}{l}\text { Scavenged by } \\
\text { Biologically Important } \\
\text { Molecules }\end{array}$ & $\leftarrow$ Optimum $_{\text {Lability }} \rightarrow$ & $\begin{array}{l}\text { Not Bind at } \\
\text { Target Site }\end{array}$ \\
\hline $\begin{array}{l}\text { Toxic } \\
\text { High Retention-Long } T_{1 / 2}\end{array}$ & & $\begin{array}{l}\text { Non-Toxic } \\
\text { Low Retention-Short } T_{1 /}\end{array}$ \\
\hline trans & cis & $\mathrm{PtA}_{4}^{2+}$ \\
\hline$k_{l}(\mathrm{rel}) \quad 3.9$ & 1 & 0 \\
\hline $\begin{array}{l}\text { Toxicity 20-30 } \\
\text { (mg/kg) }\end{array}$ & 10 & $\sim 800$ \\
\hline$T_{1 / 2}$, hrs & & $3 \cdot 2$ \\
\hline
\end{tabular}

Fig. 4. "Window of lability" concept. Active complexes lie within a window (or range) of labilities centered between the extremes of complexes which are too labile (toxic) and too inert (active). The window is thought to be centered on the lability for cisplatin.

second- and third-row elements attractive and effective as chemotherapeutic agents. Presumably, these same properties play a role in the mutagenicity and mild carcinogenicity observed for cisplatin and the mutagenicity noted for other substitutionally-inert complexes [e.g., $\mathrm{Cr}$ (III), $\mathrm{Rh}$ (III)] [9].

Optimal lability/window of lability concept

A prime example of the importance of lability is in the area of platinum antitumor chemistry. Comparison of the activity and lability of a series of closely related cisplatin analogs supports the contention that there is a Window of Lability (Fig 4) [10]. Complexes exhibiting a lability falling within this window (which is centered on the lability of cisplatin) can be expected to exhibit optimal antitumor activity. For complexes with labilities falling outside this window, either the complexes are too labile (and presumably are indiscriminately scavenged by a host of biomolecules) or are too inert (i.e., either do not bind at the target site or bind at a rate sufficient to elicit an observable response).

Metal systems [other than $\mathrm{Pt}(\mathrm{II})$ ] which appear to have labilities falling within this window and therefore might be expected to give rise to antitumor active complexes are also tabulated in Table 3. 


\section{Lability of $\mathrm{d}^{8}$ square-planar complexes}

The relative order of lability of the $d^{8}$ square-planar M(II) systems of Group VIIIA is: $\mathrm{Ni}\left(5 \times 10^{6}\right)>\mathrm{Pd}\left(1 \times 10^{5}\right) \gg \mathrm{Pt}(1.0)$. It is believed that the lack of antitumor activity of the analogous $\mathrm{Ni}$ (II) and Pd(II) complexes is directly related to the much higher labilities of these systems. This exceedingly higher lability may translate into the fact that (i) either the complexes of $\mathrm{Ni}$ (II) and $\mathrm{Pd}(\mathrm{II})$ react so rapidly that they do not retain their identity (and critical cis-geometry) in vivo, or (ii) if they manage to bind to DNA intact (cisplatin is a DNA binder) the metal-DNA lesion formed is probably unable to retain its integrity sufficiently long to allow the antitumor response to be elicited (i.e., for the "lesion" to be expressed).

\section{Tissue distribution/retention}

Studies of the distribution/retention of the series of chloroammineplatinum(II) complexes, $\left[\mathrm{Pt}\left(\mathrm{NH}_{3}\right)_{4-X} \mathrm{Cl}_{X}\right]^{2-X}$, in the rodent reveal that tissue levels as $\mu \mathrm{g} \mathrm{Pt} / \mathrm{g}$ tissue) generally increase in the order [11]: $\left(\mathrm{A}=\mathrm{NH}_{3} ; X=1-4\right)$

$$
\underset{\text { cis }}{\left[\mathrm{PtA}_{4}\right]^{2+}<\left[\mathrm{PtA}_{3} \mathrm{Cl}\right]^{+}<\left[\mathrm{PtA}_{2} \mathrm{Cl}_{2}\right]^{0}<\left[\mathrm{PtACl}_{3}\right]^{-} \leqslant\left[\mathrm{PtA}_{2} \mathrm{Cl}_{2}\right]^{0}<\left[\mathrm{PtCl}_{4}\right]^{2-}}
$$

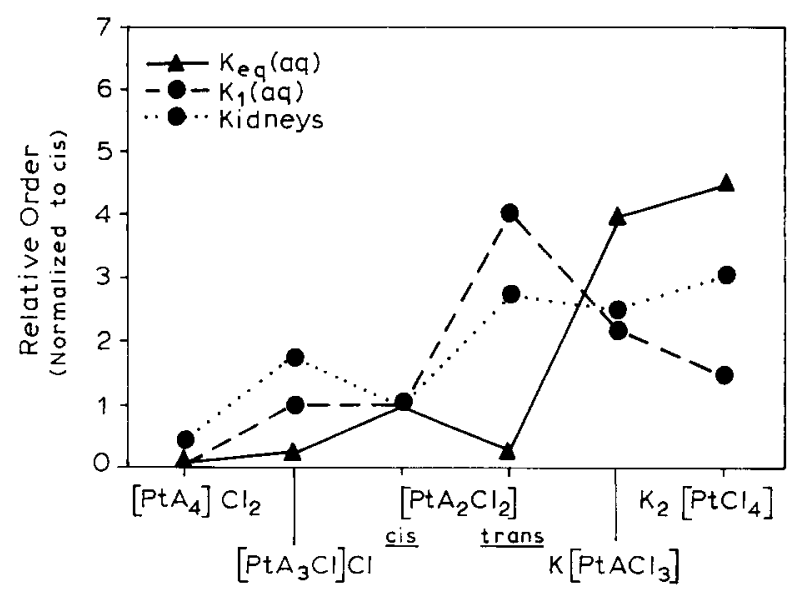

Fig. 5. Comparison of the order of chloroammineplatinum(II) compound retention ( $\mu \mathrm{g} / \mathrm{g}$ tissue) in the kidney with rate $\left(k_{1}\right)$ and equilibrium $\left(K_{\mathrm{eq}}\right)$ constants for aquation. For cis- $\mathrm{Pt}\left(\mathrm{NH}_{3}\right)_{2} \mathrm{Cl}_{2}$, the aquation reaction would be:

cis- $\mathrm{Pt}\left(\mathrm{NH}_{3}\right)_{2} \mathrm{Cl}_{2}+\mathrm{H}_{2} \mathrm{O} \underset{k_{2}}{\stackrel{k_{1}}{\rightleftharpoons}}$ cis $\left[\mathrm{Pt}\left(\mathrm{NH}_{3}\right)_{2} \mathrm{Cl}\left(\mathrm{H}_{2} \mathrm{O}\right)\right]^{+}+\mathrm{Cl}^{-}$

where $K_{\text {eq }}=k_{1} / k_{2}$. Equilibrium, rate and retention data are normalized relative to $c i s-\mathrm{Pt}\left(\mathrm{NH}_{3}\right)_{2} \mathrm{Cl}_{2}$. Equimolar amounts of labeled $\left({ }^{195 \mathrm{~m}} \mathrm{Pt}\right)$ complexes were administered i.v. in obtaining the tissue data. 
This order more closely parallels trends in the kinetic rate constants, $k_{1}$, rather than the thermodynamic equilibrium constants, $K_{\text {eq }}$ (Fig. 5), for the first step in the generalized aquation reaction (Eqn 1):

$\left[\mathrm{PtA}_{4-X} \mathrm{Cl}_{X}\right]^{2-X}+\mathrm{H}_{2} \mathrm{O} \underset{k_{2}}{\stackrel{k_{1}}{\rightleftharpoons}}\left[\mathrm{PtA}_{4-X} \mathrm{Cl}_{X-1}\left(\mathrm{H}_{2} \mathrm{O}\right)\right]^{3-X}+\mathrm{Cl}^{-}$

where $K_{\mathrm{eq}}=k_{1} / k_{2}$. The results indicate that kinetic factors, as might have been expected a priori, play a dominant role in the binding/retention and potential activity/toxicity of $\mathrm{Pt}(\mathrm{II})$ (and perhaps other substitution-inert transition metal complexes) in vivo. The results also suggest that the uptake/ retention of labile metal systems [excluding possibly those metal ions (e.g., $\mathrm{K}^{+}, \mathrm{Na}^{+}$) for which the levels are physiologically controlled] will be thermodynamically controlled and will be bound to sites/substrates incorporating the most stable metal-ligand (M-L) bonds (vide infra).

\section{THERMODYNAMIC STABILITY OF METAL COMPLEXES}

Considerations of the thermodynamic stability of metal complexes allows us to understand/predict the (i) specific preferences of a metal ion system for a given type of ligand and (ii) the strength of the metal-ligand bonds. At least four major factors contribute to the stability of a metal complex:

(i) electron acceptor properties of the metal system (Lewis acid)

(ii) electron donor properties of the donor atom ligand (Lewis base)

(iii) electrostatic interaction

(iv) $\pi$-donor acceptor capabilities ( $\pi$ vs $\sigma$ bonding)

The thermodynamic stability of a metal complex in solution is measured in terms of its stability $\left(K_{\mathrm{n}}\right)$ or formation $\left(K_{\mathrm{f}}\right)$ constant. The formation (and dissociation) of complexes in solution involves a series of stepwise equilibria (Fig. 6) for which the stepwise constants are designated as $K_{\mathrm{n}}$ and the overall

$$
\begin{array}{ll}
M+A=M A & \beta_{1}=\frac{[M A]}{[M][A]} \\
M+2 A \rightleftharpoons M A_{2} & \beta_{2}=\frac{\left[M A_{2}\right]}{[M][A]^{2}} \\
M+3 A=M A_{3} & \beta_{3}=\frac{\left[M A_{3}\right]}{[M][A]^{3}} \\
M+n A=M A_{n} & \beta_{n}=\frac{\left[M A_{n}\right]}{[M][A]^{n}}
\end{array}
$$

$\beta$ is the Product of the Stepwise Formation Constants:
$\beta_{4}=K_{1} K_{2} K_{3} K_{4}$ and $\beta_{n}=K_{1} K_{2} K_{3} \ldots K_{n}$

Fig. 6. Overall function constants $\left(\beta_{\mathrm{n}}\right)$ for the formation of complexes of the general type, $\mathrm{MA}_{\mathrm{n}}$, where $n=1-n$. These constants are a quantitative measure of the stability of a metal complex in solution. 
stability constants as $\beta_{\mathrm{n}}$. Standard methods [12] are available for determining $K_{\mathrm{n}}$ (or $\beta_{\mathrm{n}}$ ), and indeed an enormous amount of stability constant data is available [13]. Knowledge of the appropriate stability data is essential in determining whether a particular ligand considered for use in ligand (or chelate) therapy can selectively remove (or reduce the toxic levels of) a given metal ion [e.g., Fe(III), Pt(II), actinides, etc.] in the body. [High metal-ligand affinity and the capability of chelation are also important considerations in this example (vide infra).]

Numerous investigations have shown that the natural order of stability of complexes of first-row divalent metals is: $\mathrm{Mn}<\mathrm{Fe}<\mathrm{Co}<\mathrm{Ni}<\mathrm{Cu}<\mathrm{Zn}$. The CFT predicts (in good agreement with experiment) that (i) the stability of a metal complex increases as $\Delta$ increases, (ii) transition metal complexes will bond preferentially to $\mathrm{NH}_{3}$ and $\mathrm{NH}_{2} \mathrm{R}$ vs $\mathrm{H}_{2} \mathrm{O}$ or other O-donor atom ligands since the CFSE (for N-donors) > CFSE (for O-donors), and (iii) alkali, alkaline earth, and lanthanide metals prefer to bind to $\mathrm{O}$-donor ligands.

\section{Hard-soft acid base theory (HSABT)}

The HSABT of Pearson [14] qualitatively predicts the preference of a metal for a ligand and the stability of $\mathrm{M}-\mathrm{L}$ bonds. According to this concept, metals fall into two categories (based on the Lewis acidity/basicity). Class (a) or "hard" metals bind to bases which strongly bind $\mathrm{H}^{+}$(hard bases). These metals are characterized by high charge/radius ratios and are non-polarizable. By contrast, Class (b) or "soft" metals have the highest affinity for highly polarizable (or unsaturated) bases. The basis of this classification is that the most stable complexes will form between ligands and metals of the same type, i.e. hard bases have the highest affinity for hard acids and, conversely, soft bases have the highest affinity for soft acids. The detailed classification of hard and soft metal ions is tabulated in Table 5.

The implications and applications of the HSABT are that one can predict with reasonable certainty the thermodynamically stable $\mathrm{M}-\mathrm{L}$ linkages. Examples of the application are as follows:

(i) Fe(III), a Class (a) or hard metal system, prefers the hard ligand, O. Thus, it is understandable that $\mathrm{Fe}(\mathrm{III})$ in the body is controlled by $\mathrm{OH}^{-}, \mathrm{O}^{2-}$, and $\mathrm{RO}^{-}$, for example as in (a) ferritin, wherein Fe(III) is bound by the phenolate group, ${ }^{-} \mathrm{OPh}$, and (b) in the great tendency of $\mathrm{Fe}$ (III) to deposit in the tissues as hydrous ferric oxide, $\mathrm{Fe}_{2} \mathrm{O}_{3} \cdot X \mathrm{H}_{2} \mathrm{O}$, in cases of excessive $\mathrm{Fe}$ uptake [15].

(ii) Pt(II), a Class (b) metal, prefers $\mathrm{N}$-donor ligands to O-donor ligands. Thus, cisplatin binds preferentially at the N-7 of guanosine in DNA, the probable putative binding site for $\mathrm{Pt}$ antitumor drugs, rather than at phosphate (O-donor) sites. 
TABLE 5

Order of affinity of donor ligands for "hard" and soft" metal ions (Lewis acids)

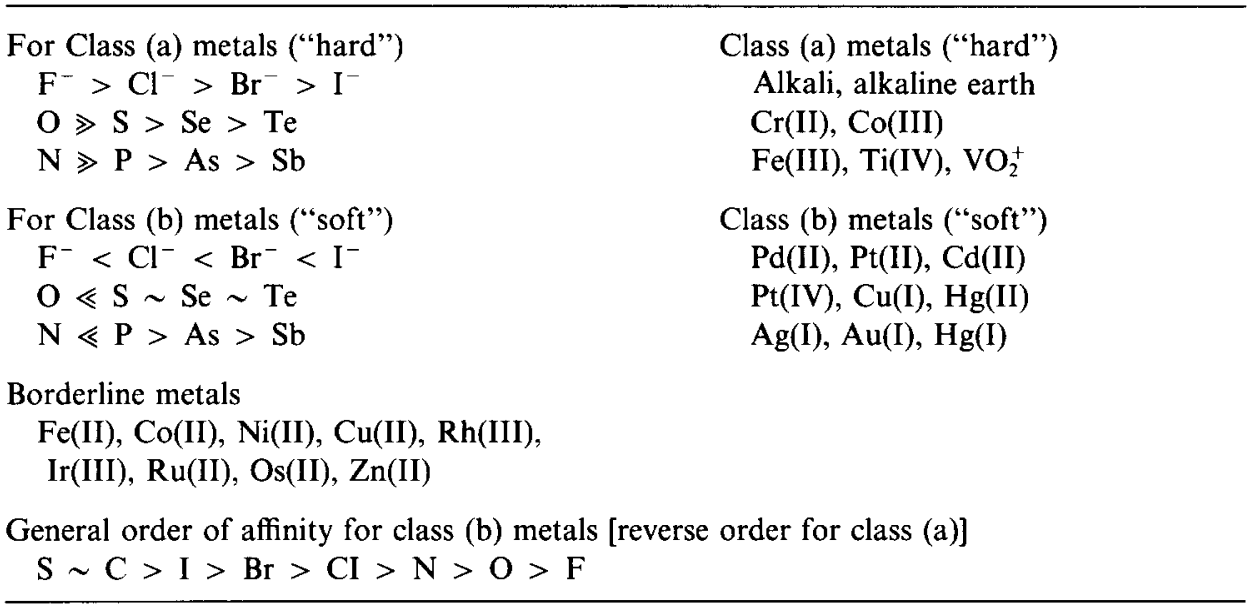

Other examples of $\mathrm{M}-\mathrm{L}$ specificities (affinities) are included in Table 6.

\section{REDOX PROPERTIES}

Metal systems capable of existing in more than one oxidation state may undergo changes in oxidation state in a biological environment as a result of

\section{TABLE 6}

Preferred ligand-binding groups for metal ions

\begin{tabular}{|c|c|}
\hline Metal & Ligand groups \\
\hline $\mathrm{K}^{+}$ & Singly-charged oxygen donors or neutral oxygen ligands \\
\hline $\mathrm{Mg}^{2+}$ & Carboxylate, phosphate, nitrogen donors \\
\hline $\mathrm{Ca}^{2+}$ & $\begin{array}{l}\equiv \mathrm{Mg}^{2+} \text {, but less affinity for nitrogen donors, phosphate and other } \\
\text { multidentate anions }\end{array}$ \\
\hline $\mathrm{Mn}^{2+}$ & Similar to $\mathrm{Mg}^{2+}$ \\
\hline $\mathrm{Fe}^{2+}$ & $-\mathrm{SH}, \mathrm{NH}_{2}>$ carboxylates \\
\hline $\mathrm{Fe}^{3+}$ & Carboxylate, tyrosine, $-\mathrm{NH}_{2}$, porphyrin (four 'hard' nitrogen donors) \\
\hline $\mathrm{Co}^{3+}$ & Similar to $\mathrm{Fe}^{3+}$ \\
\hline $\mathrm{Cu}^{+}$ & $-\mathrm{SH}$ (cysteine) \\
\hline $\mathrm{Cu}^{2+}$ & Amines $\gg$ carboxylates \\
\hline $\mathrm{Zn}^{2+}$ & Imidazole, cysteine \\
\hline $\mathrm{Mo}^{2+}$ & $-\mathrm{SH}$ \\
\hline $\mathrm{Cd}^{2+}$ & $-\mathrm{SH}$ \\
\hline $\operatorname{Pt}(\mathrm{II})$ & $-\mathrm{SH}, \mathrm{N}$-donors (N-7 or guanosine) \\
\hline $\mathrm{Au}(\mathrm{I})$ & -SH (cysteine) \\
\hline
\end{tabular}


encountering local oxidizing and/or reducing environments. In general, the moderate reduction potential of a biological system would tend to convert metals to lower oxidation states; however, oxidation (e.g., by $\mathrm{O}_{2}$; $E_{0}^{1}=+082 \mathrm{mV}$ at $\mathrm{pH} 7$ ) could promote some metals to higher oxidation states. Since the redox potential of a metal system is a function of both the nature of the metal and the ligands attached to it (and potentially a function of $\mathrm{pH}$ and ionic strength), a priori it is difficult to predict with absolute certainty the redox fate of a metal ion or complex in a biological system (unless, of course, the redox potential of a given species is known under physiological/environmental conditions).

Redox changes producing new (or multiple) species can have a pronounced influence on the overall toxicological (biological) response elicited by the metal system. This is clearly evident in the case of mercury, which can exist in two oxidation states plus the free state. The individual $\mathrm{Hg}$ species exhibit marked differences in uptake, distribution, and toxicological effects. A single redox change in vivo involving any one of these species could lead to the production of all three forms as governed by the following disproportionation reaction (Eqn 2):

$2 \mathrm{Hg}(\mathrm{I}) \rightleftharpoons \mathrm{Hg}^{0}+\mathrm{Hg}(\mathrm{II})$

Thus, redox reactions, as in this example, can compound the toxicological effects of an otherwise single form of the metal system.

Redox changes in vivo can lead to modification of the intrinsic lability/reactivity of the product(s) of the redox reaction. Specifically, an inert reactant can become a labile product (and vice versa) which in turn can lead to further chemical and/or biological events. The classical redox reaction of Taube (Eqn 3) provides some insight into the type of events which could accompany metal redox reactions in a biological system.

$\left[\mathrm{Co}\left(\mathrm{NH}_{3}\right)_{5} \mathrm{X}\right]^{2+}+\mathrm{Cr}_{\text {(aq) }}^{2+}+5 \mathrm{H}^{+} \rightarrow\left[\mathrm{Cr}\left(\mathrm{H}_{2} \mathrm{O}\right)_{5} \mathrm{X}\right]^{2+}+\mathrm{Co}_{\text {(aq) }}^{2+}+5 \mathrm{NH}_{4}^{+}$

The two salient features of this reaction are: (i) reduction of the inert $\mathrm{Co}(\mathrm{III})$ species by labile $\mathrm{Cr}$ (II) leads to labile $\mathrm{Co}$ (II) and an inert $\mathrm{Cr}$ (III) species as products and, perhaps equally importantly, (ii) the ligand, $\mathrm{X}$, is transferred to, and is retained in, the coordination sphere of the newly formed inert complex, $\left[\mathrm{Cr}\left(\mathrm{H}_{2} \mathrm{O}\right)_{5} \mathrm{X}\right]^{2+}$. The implication of the Taube reaction as regards metalbiological redox reactions is that redox reactions which lead to a change in the lability of the metal system (i.e., formation of an inert product from a labile reactant) may result in critical biological ligands/sites (e.g., nucleic acids, proteins) becoming strongly (if not irreversibly) bonded to subsitutionallyinert complexes. Depending on the strength and nature of the $\mathrm{M}-\mathrm{L}$ bonds, the metal may not be removed easily via the normal substitution reactions and/or even, perhaps, via repair processes. A case in point is, perhaps, the biological 
fate of $\mathrm{Cr}(\mathrm{VI})$. The mutagenic and strong oxidant $\mathrm{CrO}_{4}^{2-}$ (or $\mathrm{Cr}_{2} \mathrm{O}_{7}^{2-}$ under acidic conditions) is ultimately reduced to the inert $\mathrm{Cr}$ (III) system. Although the nature of the resulting $\mathrm{Cr}$ (III) complex is unknown, there is evidence suggesting that DNA binding could be involved [16]. If true, this could account for the mutagenicity of $\mathrm{Cr}$ (VI), but the actual mutagenic agent might indeed be $\mathrm{Cr}(\mathrm{III})$. A second example of a redox reaction producing an inert product from a labile reactant is the potential in vivo oxidation of the less inert $\mathrm{Ru}(\mathrm{II})$ to the more inert $\mathrm{Ru}(\mathrm{III})$, which could have the effect of strengthening a potential $\mathrm{Ru}-\mathrm{DNA}$ linkage [17].

Potential in vivo redox reactions involving highly inert systems [e.g., $\mathrm{Pt}(\mathrm{IV})]$ may result in the formation of the less inert and, in specific cases, biologically active cis- $\mathrm{Pt}(\mathrm{II})$ complexes. For example, it has been shown recently that indeed $c i s$ - $\left[\mathrm{Pt}\left(\mathrm{i}-\mathrm{PrNH} \mathrm{N}_{2}\right)_{2} \mathrm{Cl}_{2}\right]$ is produced and can be detected in the urine of mice following intraperitoneal administration of the $\mathrm{Pt}(\mathrm{IV})$ complex cis-trans-[ $\left.\mathrm{Pt}(\mathrm{i}-\mathrm{PrNH})_{2}(\mathrm{OH})_{2} \mathrm{Cl}_{2}\right]$. This lends some credence to the notion that antitumor-active $\mathrm{Pt}(\mathrm{IV})$ complexes derive their activity via a stereospecific reduction in vivo to the corresponding active $\mathrm{Pt}(\mathrm{II})$ entities.

PHYSICAL PARAMETERS (Softness Parameters)

It has been the goal of several research groups to understand and identify the key factors which contribute to the toxicity of various metal compounds and to try to correlate the toxicity of these metal compounds with a suitable indicator of toxicity, i.e. either a single parameter or a multiparameter expression involving basic physical (periodic) properties. This is being carried out with the expectation that at some point one will be able to predict the toxicity of all potential metal toxicants of interest and in so doing make valuable input into the notion of "Chemical Dosimetry." The most successful correlations (i.e., highest correlation coefficients, $r$ ) are those involving the so-called softness parameters, expecially $\sigma_{\mathrm{p}}$. Pearson and Mawby [18] have defined $\sigma_{\mathrm{p}}$ for a metal ion in terms of the coordinate bond energies of its metal fluoride, $\mathrm{CBE}(\mathrm{F})$, and metal iodide, $\mathrm{CBE}(\mathrm{I})$ by the expression

$$
\sigma_{\mathrm{p}}=\frac{\mathrm{CBE}(\mathrm{F})-\mathrm{CBE}(\mathrm{I})}{\mathrm{CBE}(\mathrm{F})}
$$

For ions of a given charge, "softness" increases as $\sigma_{\mathrm{p}}$ decreases. Tight correlations (high $r$ values) are observed, essentially, only for the alkali metals since even within the closely related alkaline earth family (Group IIA), Be(II) persists as a serious outlier. Thus, as yet, no set of parameters correlates adequately metal compounds of a dissimilar nature. As an example of the best degree of correlation obtained thus far with softness paremeters, the $\mathrm{LD}_{50}$ values for 15 divalent metal ions are plotted against $\sigma_{\mathrm{p}}$ in Fig. 7. The plot 


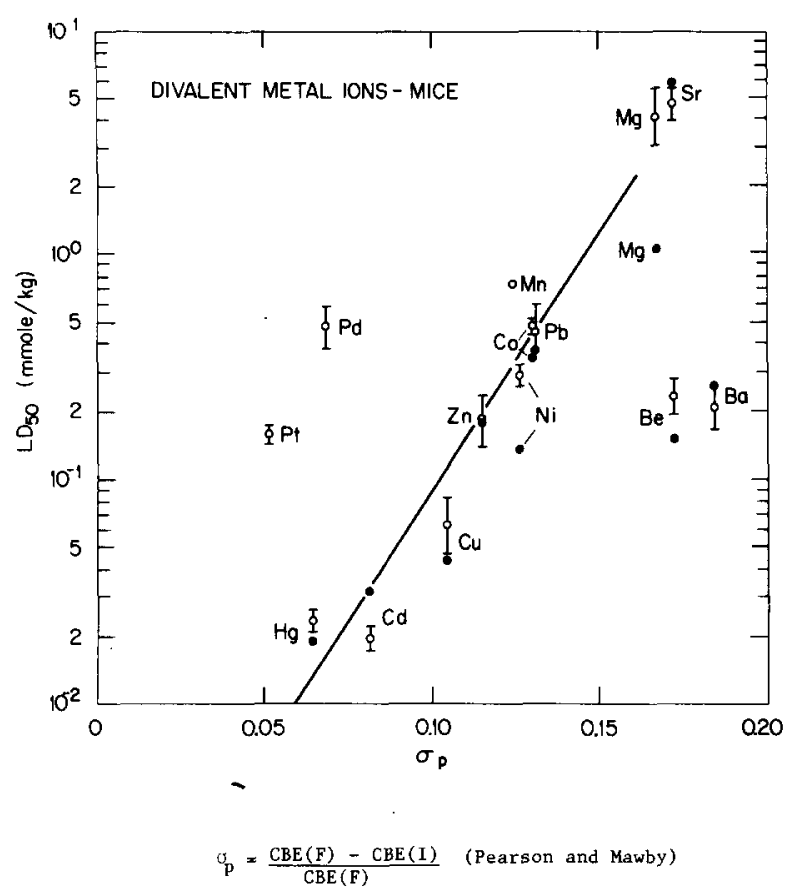

Fig. 7. $\mathrm{LD}_{50}$ values for mice for divalent metal ions as a function of the softness parameter, $\sigma_{\mathrm{p}}$. (O) Data of Williams et al. [19]; (•) data from Jones and Vaughn [20] and Williams and Turner [21].

(correlation coefficient of 0.767 ) includes the data of Williams et al. [19] and Jones and Vaughn [20].

It is apparent that other parameters (or a combination of parameters) must be sought in order to gain a better understanding of the toxicity of metals. Since many basic factors contribute to the overall toxic response of metals, factors other than basic physical parameters need to be taken into account such as those related to the basic chemistry, nature of the potential metalbiological interaction, and pharmocokinetic considerations.

\section{REFERENCES}

1 F. Basolo and R.G. Pearson, Mechanism of Inorganic Reactions, J. Wiley and Sons, Inc., New York, 1967, pp. 65-69. Material for the CFT was taken principally from this reference.

2 H. Bethe, Ann. Phys., 3 (1929) 133.

3 L.E. Orgel, J. Chem. Soc., (1952) 4756.

4 Reference 1, p. 65.

5 C.K. Jorgensen, Absorption Spectra and Chemical Bonding, Pergamon Press, 1961; D.F. Shriver and S. E. Anderson, Inorg. Chem., 4 (1965) 324.

6 R.S. Nyholm, Proc. Chem. Soc., (1961) 273.

7 Reference 1, p. 141.

8 N.S. Hush, Aust. J. Chem., 15 (1962) 378; Ref. 1, p. 148. 
9 G. Warren, S.J. Rogers and E.H. Abbott, American Chemical Society Symposium Series No. 140, Inorganic Compounds in Biology and Medicine, 1980, Chapt. 13, pp. 227-236.

10 M.J. Cleare and J.D. Hoeschele, Bioinorg. Chem., 2 (1973) 187-210.

11 J.D. Hoeschele, T.A. Butler and J.A. Roberts, American Chemical Society Symposium Series No. 140, Inorganic Compounds in Biology and Medicine, 1980, Chapt. 11, pp. 182-208.

12 F.J.C. Rossotti and H. Rossotti, Determination of Stability Constants and Other Equilibrium Constants in Solution, McGraw-Hill, New York, 1961.

13 A.E. Martell and R.M. Smith, Critical Stability Constants, Vol 1-6, Plenum Press, New York, pp. 1974-1989.

14 R.G. Pearson, J. Am. Chem. Soc., 85 (1963) 3533; Science, 151 (1966) 172.

15 C.G. Pitt and A.E. Martell, American Chemical Society Symposium Series, No. 140, Inorganic Compounds in Biology and Medicine, 1980, Chapt. 17. p. 279.

16 K.M. Borges and K.E. Wetterhahn, Carcinogenesis, 10 (1989) 2165-2168.

17 M.J. Clarke, personal communication.

18 R.G. Pearson and R.J. Mawby, In: V. Gutmann (Ed.). Halogen Chemistry, Vol. 3, 1967, pp. 55-84.

19 M.W. Williams, J.D. Hoeschele, J.E. Turner, K.B. Jacobson, N.T. Christie, C.L. Paton, L.H. Smith, H.R. Witschi and E.H. Lee, Toxicol. Appl. Pharmacol., 63 (1982) 461-469.

20 M.M. Jones and W.K. Vaughn, J. Inorg. Nucl. Chem., 40 (1978) 208-2088.

21 M.W. Williams and J.E. Turner, J. Inorg. Nucl. Chem., 43. (1981) 1689-1691.

22 M. Eigen, Z. Elektrochem., 64 (1960) 115. 